\title{
To block it, or not to block it?
}

\author{
Artur Wnorowski ${ }^{1}$ (1)
}

Received: 2 March 2017 / Accepted: 14 March 2017 / Published online: 27 March 2017

(C) The Author(s) 2017. This article is an open access publication

\section{To Editor,}

In a recent issue of Journal of Cancer Research and Clinical Oncology, Coelho et al. (2017) reviewed preclinical and epidemiological reports regarding changes in cellular proliferation in response to $\beta$-adrenergic receptor ( $\beta$-AR) ligands. The authors indicated that cancer cells commonly express both $\beta_{1}$ and $\beta_{2}$ adrenoceptors and that the agonistmediated activation of these receptors leads to increased proliferation of cultured cells of different origin. Consequently, $\beta$-blockers ( $\beta$-AR antagonists) were proposed as adjuvants for cancer management. This was supported by numerous pharmacoepidemiological studies indicating that cancer patients experience beneficial effects like prolonged survival or reduced risk of metastasis due to chronic $\beta$-blocker intake for cancer-unrelated heart conditions (Barron et al. 2011; Lemeshow et al. 2011).

As noted by the authors, the amount of data generated over time strongly supports the notion that blockage of $\beta$-ARs may constitute a novel therapeutic option for cancer. However, a non-negligible body of evidence indicates that opposite measures-i.e. activation of $\beta$-AR - may also be effective in suppressing the growth of cancer cells, at least in some cases (Strell et al. 2012). Thus, the purpose of this letter is to highlight the studies demonstrating antitumorigenic effects of $\beta$-AR activation, as opposed to $\beta$-blocker

This comment refers to the article available at doi:10.1007/ s00432-016-2278-1.

Artur Wnorowski

artur.wnorowski@umlub.pl

1 Department of Biopharmacy, Medical University of Lublin, Collegium Pharmaceuticum, Chodzki 4a01a, 20-093 Lublin, Poland usage. To start with, high-grade brain tumors are characterized by low activity of adenylyl cyclase and/or depletion of cytoplasmic cAMP. Concomitantly, glioma and astrocytoma cell lines like A-172 and $1321 \mathrm{~N} 1$ are highly susceptible to increased production of cAMP, which can be achieved by treatment with cAMP analogues, adenylyl cyclase activators or phosphodiesterase inhibitors (Chen et al. 1998; Toll et al. 2011). It is not surprising that agonists of $\beta$-AR can mimic the antiproliferative effects of the above-mentioned compounds, as canonical $\beta$-AR signaling pathway involves the $\mathrm{G}_{\mathrm{s}}$-dependent activation of adenylyl cyclase and subsequent accumulation of cAMP (Toll et al. 2011). In our study carried out in $1321 \mathrm{~N} 1$ cells, the level of cAMP induced by the $\beta_{2}$-AR agonists like fenoterol and isoproterenol positively correlated with decreased mitogenesis (Fig. 1). Similarly, decreased cell growth was observed in response to $\beta$-AR agonists in nontumor breast MCF-10A cells (Bruzzone et al. 2014) and in breast cancer cell line MDA-MB-231 (Carie and Sebti 2007). In significance, Gargiulo et al. demonstrated that $\beta_{2}$-AR knock-down led to increase of cell proliferation and migration of MCF-7 breast cancer cell line, indicating that $\beta_{2}$-AR exerts an inhibitory tone towards cell growth and motility at basal conditions (Gargiulo et al. 2014). When the same cell line was engineered to overexpress $\beta_{2}$-AR, significant drop in cell growth and migration was observed (Gargiulo et al. 2014). In line with this work, our unpublished data on rat C6 glioma cells indicate that siRNA-mediated depletion of $\beta_{2}$-AR leads to significant increase in phosphoactive forms of AKT and ERK1/2. Taken together, expression level of the $\beta_{2}$-AR receptor is an important factor shaping the proliferative capacity of cancer cells, and should be taken into account when studying the cellular responses to $\beta_{2}$-AR ligands. 


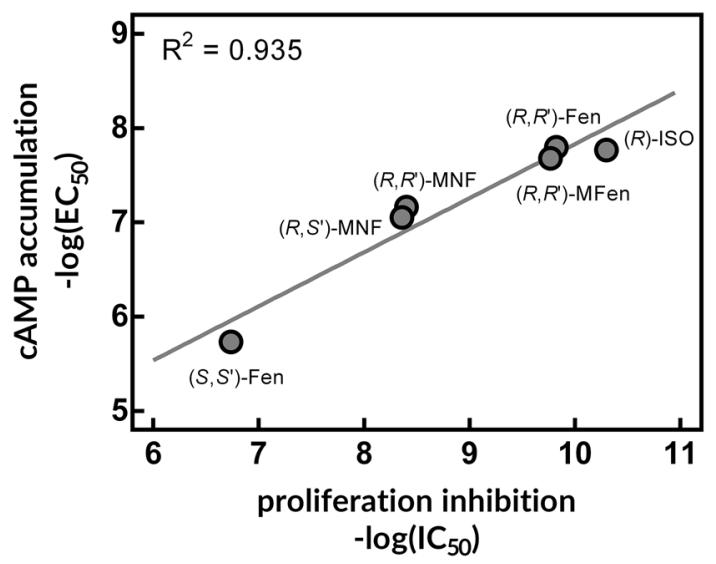

Fig. 1 Antiproliferative effects of $\beta_{2}$-AR agonists in 1321N1 astrocytoma cells. Selected $\beta_{2}$-AR agonists were tested for the cAMP accumulation and for the $\left[{ }^{3} \mathrm{H}\right]$ thymidine incorporation in $1321 \mathrm{~N} 1$ cells. Linear regression demonstrated that compounds more potent according to the capacity to induce cAMP production were also better inhibitors of thymidine incorporation. ISO isoproterenol, Fen fenoterol, MFen 4'-methoxyfenoterol, MNF 4'-methoxy-1-naphthylfenoterol. The graph was generated by plotting the data retrieved from the work of Toll et al. (2011)

Results from developmental studies also contribute to the knowledge on $\beta$-AR function in highly proliferative cells. Activation of $\beta$-ARs in murine embryonic pluripotent stem cells inhibits proliferation and cell cycle progression via cAMP and PKA (Sun et al. 2015). This is consistent with the finding that propranolol treatment in Xenopus laevis embryos encourages a neoplastic-like phenotype characterized by hyperpigmentation and increased melanocyte count (Sullivan and Levin 2016). We made compatible observations in human-derived UACC-647, M93-047 and UACC-903 melanoma cells: treatment with $\beta_{2}$-AR agonists (isoproterenol, fenoterol) markedly delayed proliferation and invasiveness of the melanoma cells (Wnorowski et al. 2015). These functional responses were accompanied by drop in ERK1/2 phosphorylation. Pharmacological approach enabled us to map the signaling pathway responsible for the observed effects to $\beta_{2}-\mathrm{AR} / \mathrm{G}_{\mathrm{s}} /$ adenylyl cyclase/cAMP/PKA (Wnorowski et al. 2015). Comparable observations were made by Bruzzone and colleagues, who identified that isoproterenol mediates its antiproliferative actions by the activation of $\beta_{2}$-AR/cAMP/PKA and boosts cell adhesion by triggering $\beta_{2}$-AR/cAMP/EPAC in human breast cells (Bruzzone et al. 2014).

Plethora of epidemiological studies indicated that cancer patients benefit from $\beta$-blockers usage. For instance, population-based cohort study from Denmark showed that $\beta$-blocker treatment reduces risk of death in malignant melanoma patients (Lemeshow et al. 2011). Similarly, Watkins et al. reported longer median overall survival in ovarian cancer patients receiving nonselective $\beta$-blockers compared to nonusers (2015). However, some other reports failed to confirm the association between $\beta$-blocker use and decreased mortality following ovarian cancer diagnosis (Eskander et al. 2012; Johannesdottir et al. 2013). It has been speculated that some of the epidemiological reports on $\beta$-blockers can suffer from the immortal person-time bias (Schmidt and Schmidt 2016). This type of statistical bias arises when exposure to $\beta$-blocker occurs after the start of follow-up (i.e. after the cancer diagnosis). In such case, the time that patients have to survive between the start of follow-up to the initiation of $\beta$-blocker intake is referred to as "immortal", as the patient needs to survive it to be classified as exposed to the drug. Inclusion of this immortal time leads to overestimation of the overall survival time in exposed group compared to nonusers (Suissa 2008). Thus, skew by an immortal time bias can constitute a probable explanation to discrepancies in retrospective pharmacoepidemiological studies on $\beta$-blocker effectiveness in ovarian cancer, and possibly in other cancer types (Weberpals et al. 2016).

\section{Conclusions}

$\beta$-Blockers are commonly used drugs with well-defined pharmacokinetic and pharmacodynamic profiles and generally mild side effects (Hilal-Dandan et al. 2017). It would be greatly appreciated if these relatively inexpensive drugs were proven effective as supportive agents in standard chemotherapy or as standalone cancer prevention agents. Hopefully, ongoing clinical trials will confirm the feasibility of $\beta$-blockers usage in cancer management. However, in some types of cancer cells an opposite approach may be more suitable. Preclinical studies indicate that in some systems agonist-mediated activation of $\beta$-ARs efficiently suppresses cellular proliferation and, thus, is more beneficial than the treatment with $\beta$-blockers. We believe that there is an urgent need to understand why some cancer cells are susceptible to $\beta$-AR antagonists, while others are attenuated by agonists of $\beta$-ARs.

We fully agree with Coelho et al. that further studies are necessary to decipher the complexity of intracellular signaling triggered by different classes of $\beta$-AR ligands. When studying effects of such compounds, one should take into account the qualitative and quantitative variability in the composition of cellular signaling machinery, including the expression level and localization of adrenoceptors (Gargiulo et al. 2014) and downstream signaling proteins (Skalhegg and Tasken 2000) in the cells of interest. Availability of non-adrenergic receptors to oligomerize with $\beta$-ARs should be also acknowledged (Wnorowski and Jozwiak 2014). Moreover, single-dose experiments should be avoided in favor of dose-ranging studies, as 
cellular responses to $\beta$-AR ligands tend to follow biphasic, bell-shaped or U-shaped curves (Bruzzone et al. 2014; Wnorowski et al. 2015). With new data being consistently generated, we may ultimately be able to predict the cellular responses of a given cell type to agonists and antagonists of $\beta$-ARs and exploit this knowledge to produce desired cellular effect, hopefully in clinically relevant manner.

Open Access This article is distributed under the terms of the Creative Commons Attribution 4.0 International License (http:// creativecommons.org/licenses/by/4.0/), which permits unrestricted use, distribution, and reproduction in any medium, provided you give appropriate credit to the original author(s) and the source, provide a link to the Creative Commons license, and indicate if changes were made.

\section{References}

Barron TI, Connolly RM, Sharp L, Bennett K, Visvanathan K (2011) Beta blockers and breast cancer mortality: a population-based study. J Clin Oncol Off J Am Soc Clin Oncol 29:2635-2644. doi:10.1200/JCO.2010.33.5422

Bruzzone A, Sauliere A, Finana F, Senard JM, Luthy I, Gales C (2014) Dosage-dependent regulation of cell proliferation and adhesion through dual $\beta 2$-adrenergic receptor/cAMP signals. FASEB J 28:1342-1354. doi:10.1096/fj.13-239285

Carie AE, Sebti SM (2007) A chemical biology approach identifies a beta- 2 adrenergic receptor agonist that causes human tumor regression by blocking the Raf-1/Mek-1/Erk1/2 pathway. Oncogene 26:3777-3788. doi:10.1038/sj.onc.1210172

Chen TC, Hinton DR, Zidovetzki R, Hofman FM (1998) Up-regulation of the cAMP/PKA pathway inhibits proliferation, induces differentiation, and leads to apoptosis in malignant gliomas. Lab Invest 78:165-174

Coelho M, Soares-Silva C, Brandao D, Marino F, Cosentino M, Ribeiro L (2017) $\beta$-Adrenergic modulation of cancer cell proliferation: available evidence and clinical perspectives. J Cancer Res Clin Oncol 143:275-291 doi:10.1007/s00432-016-2278-1

Eskander R, Bessonova L, Chiu C, Ward K, Culver H, Harrison T, Randall L (2012) Beta blocker use and ovarian cancer survival: a retrospective cohort study. Gynecol Oncol 127:S21 doi:10.1016/j.ygyno.2012.07.059

Gargiulo L et al (2014) Differential beta(2)-adrenergic receptor expression defines the phenotype of non-tumorigenic and malignant human breast cell lines. Oncotarget 5:10058-10069

Hilal-Dandan R, Knollman B, Brunton L (2017) Goodman and Gilman's The Pharmacological Basis of Therapeutics, 13th Edition. McGraw-Hill Education
Johannesdottir SA, Schmidt M, Phillips G, Glaser R, Yang EV, Blumenfeld M, Lemeshow S (2013) Use of $\beta$-blockers and mortality following ovarian cancer diagnosis: a population-based cohort study. BMC Cancer 13:85. doi:10.1186/1471-2407-13-85

Lemeshow S et al (2011) beta-Blockers and survival among Danish patients with malignant melanoma: a population-based cohort study. Cancer Epidemiol Biomarkers Prev 20:2273-2279. doi:10.1158/1055-9965.EPI-11-0249

Schmidt SA, Schmidt M (2016) Beta-blockers and improved survival from ovarian cancer: New miracle treatment or another case of immortal person-time bias? Cancer 122:324-325. doi:10.1002/ cncr.29721

Skalhegg BS, Tasken K (2000) Specificity in the cAMP/PKA signaling pathway. Differential expression, regulation, and subcellular localization of subunits of PKA. Front Biosci J Virtual Library 5:D678-D693

Strell C, Niggemann B, Voss MJ, Powe DG, Zanker KS, Entschladen F (2012) Norepinephrine promotes the beta1-integrin-mediated adhesion of MDA-MB-231 cells to vascular endothelium by the induction of a GROalpha release. Mol Cancer Res MCR 10:197207. doi:10.1158/1541-7786.MCR-11-0130

Suissa S (2008) Immortal time bias in pharmaco-epidemiology. Am J Epidemiol 167:492-499. doi:10.1093/aje/kwm324

Sullivan KG, Levin M (2016) Neurotransmitter signaling pathways required for normal development in Xenopus laevis embryos: a pharmacological survey screen. J Anatomy 229:483-502 doi:10.1111/joa.12467

Sun F et al (2015) $\beta 2$-Adrenoreceptor-mediated proliferation inhibition of embryonic pluripotent stem cells. J Cell Physiol 230:2640-2646. doi:10.1002/jcp.24937

Toll L et al (2011) $\beta 2$-adrenergic receptor agonists inhibit the proliferation of $1321 \mathrm{~N} 1$ astrocytoma cells. J Pharmacol Exp Ther 336:524-532. doi:10.1124/jpet.110.173971

Watkins JL et al (2015) Clinical impact of selective and nonselective beta-blockers on survival in patients with ovarian cancer. Cancer 121:3444-3451. doi:10.1002/cncr.29392

Weberpals J, Jansen L, Carr PR, Hoffmeister M, Brenner H (2016) Beta blockers and cancer prognosis - the role of immortal time bias: a systematic review and meta-analysis. Cancer Treatment Rev 47:1-11 doi:10.1016/j.ctrv.2016.04.004

Wnorowski A, Jozwiak K (2014) Homo- and hetero-oligomerization of $\beta 2$-adrenergic receptor in receptor trafficking, signaling pathways and receptor pharmacology. Cell Signal 26:2259-2265. doi:10.1016/j.cellsig.2014.06.016

Wnorowski A et al (2015) Activation of $\beta 2$-adrenergic receptor by $\left(R, R^{\prime}\right)-4^{\prime}$-methoxy-1-naphthylfenoterol inhibits proliferation and motility of melanoma cells. Cell Signal 27:997-1007. doi:10.1016/j.cellsig.2015.02.012 